\title{
Research on the measures of regulating the order of tourism market in Yunnan province from the perspective of government regulation
}

\author{
Hong Haozhong \\ Yunnan University of Finance and Economics \\ holmanhong@hotmail.com
}

\begin{abstract}
-government regulation is an important measure to protect consumers' basic rights and interests and the quality of consumption products. Since April 2017, Yunnan Province has effectively dealt with outstanding problems in the tourism market and regulated market behavior through 22 measures in seven aspects aimed at regulating the order of the tourism market. In the face of new situation and problems after the implementation of the new policy, Yunnan tourism market needs to further strengthen and improve government regulation to promote the transformation and upgrading of Yunnan tourism industry.
\end{abstract}

Keywords-Government regulation; tourism market; regulatio n measures; Yunnan province

\section{EFFECT ON THE MEASURES OF REGULATING THE ORDER OF TOURISM MARKET IN YUNNAN PROVINCE}

On April 15, 2017, the people's Government of Yunnan Province promulgated the "measures for regulating the order of the tourism market in Yunnan province", which focused on tourism shopping, "low price tour", tour guide service quality, scenic spot management and supervision mechanism, the functions of trade associations and the supervision responsibilities of governments at all levels to purge the tourism industry in Yunnan, through 22 articles to contain the persistent disease of the tourism market all the time, hard to rectify the chaos of the tourism market, speed up the transformation and upgrading of the tourism industry in Yunnan Province, it is generally referred to by the outside world as "the most severe measures of tourism regulation in history."

Through more than a year of governance, effect on the measures of regulating the order of tourism market in Yunnan province is remarkable, the tourism environment is gradually improved, and tourism industry transformation and upgrading has begun to take shape, tourism industry has been further developed. In 2017, the province received a total of 6.6769 million overseas tourists, an increase of 11.2 percent over the same period last year; foreign exchange income from tourism totaled 3.55 billion US dollars, an increase of 15.55 percent over the same period last year.

\section{NEW SITUATION AND NEW PROBLEMS FACED BY THE}

\section{MEASURES TO REGULATE THE ORDER OF \\ THE TOURISM MARKET IN YUNNAN PROVINCE}

Because of the long chain of tourism industry, these are some new situations and new problems that have emerged after the implementation of the measures to regulate the order of the tourism market in Yunnan province.

\section{A.It is difficult to cut off the grey interests of the tourism} industry

According to the relevant regulations of the order regulation of tourism market in Yunnanprovince, Yunnan has completely abolished the tourism fixed point shopping, brought the tourist shopping shop into the management of the social retail commodity enterprise, and recovered all 166 tourist shopping places grade evaluation plaque; The new tourism contract has been implemented, and the travel agency 
has been prohibited from designating specific shopping places by means of contract agreement. Although these measures have produced certain effects, it is still difficult to cut off the "grey interest chain" of the tourism industry.

Tourist shopping, as the core of the "grey interest chain" in the tourism industry, has always been the worst disaster area for tourists to complain about tour guides, travel agencies and scenic spots. In particular, Yunnan's unique jade jadeite, Marka medicinal materials and other tourism products are high complaint rate of tourism shopping products. The complaints of this kind of tourism products are mainly characterized by inferior quality, shoddy goods, false price and enticing purchase. From low price shopping groups of a few hundred yuan to pure play groups of thousands yuan, travel agencies will arrange a variety of shopping links, the main shopping content is tea, jade and medicinal materials and other large bargaining space goods. The reason for frequent tourism complaints is not "zero negative tour fees," even if the payment of thousands of yuan, there will still be unreasonable shopping links. The scam behavior of shopping points, tour guides and travel agency, as well as shoddy goods and false price of tourism products are the key to the difficulty of cutting off the "grey interest chain".

\section{B.There are still guides defy the law under high pressure}

Since April 15, 2017, Yunnan Province has stepped up the investigation of illegal and irregular conducts of tour guides, investigated and dealt with 163 illegal and irregular guides; dealt with cases of forced consumption of tour guides by "conduction transferring punishment". A series of measures to regulate the guide behavior, but under the pressure of numerous policies, there are still guides desperate to break the law.

As the center of complaints in the tourism market, tour guides occupy a core position in the process of carrying out team tourism activities, and have the most contact with tourists, so the quality of service and the level of service have the greatest impact on tourists. Although Yunnan has increased the "unreasonable low price tour" rectification efforts, strictly investigate the illegal and irregular operation of travel agencies, in order to protect the rights and interests of tour guides, but because of the low entry threshold of tour guides and non-standard management system, leading to a low quality of tour guides. At the same time, the income is not fixed, mainly depends on the gray income, such as shopping rebates, which makes it difficult to curb the emergence of forced tourist shopping by tour guides.

\section{C.There are too many regulatory bodies in the tourism} market regulation

Tourism is an important economic pillar industry in Yunnan, accounting for about 7\% of Yunnan's GDP. However, in recent years, all kinds of problems in Yunnan tourism industry highlight, in addition to the tourism market of disorderly competition, trading fraud, forced sale, the lack of regulation and control of tourism market is to blame.

However, there are too many departments involved in the relevant government regulation policies, so it is difficult to inspect and inspect the performance of duties of various departments, which can easily lead to the departments to shirk their responsibility. In the event of major travel-related incidents, the supervisory departments must promptly initiate supervision and accountability procedures, and there are still difficulties in obtaining evidence.

\section{SUGGESTIONS ON FURTHER STRENGTHENING AND PERFECTING THE GOVERNMENT REGULATION}

\section{OF TOURISM INDUSTRY IN YUNNAN PROVINCE}

In response to the new situation and problems arising from the implementation of the measures to regulate the order of the tourism market in Yunnan Province, it is necessary to further strengthen and improve the government regulation of the tourism industry from the following aspects.

\section{A. Standardizing the sales of tourist products}

Yunnan Province should attach great importance to tourism shopping links. First, the units, enterprises and stalls of tourism purchase items should be included in the key control scope of tourism law enforcement. Second, we should carry out the construction of shopping shops and strengthen the examination and approval of tourist shopping enterprises. Third, promote and cultivate the production of high-quality tourism commodities actively, innovative integration into local culture, so that tourism shopping out of profiteering fraud and other 
bad image, promote the transformation and upgrading of tourism products production enterprises.

\section{B.Strengthening the training and management of tour guide}

Tour guides are the focus of tourism complaints, mainly because tour guides are often the subject of forced shopping, deception and abuse of tourists. The first is to speed up the implementation of the system of free practice of tour guides, appropriately develop the tip system for tour guides, and break the traditional dependency relationship between tour guides and travel agencies.The second is to take the satisfaction of tourists as the guideline for the salary of tour guides and the standard of their assessment and rating, and strengthen the effect of tourist evaluation on the performance management of tour guides and the promotion of their ranks.the third is to strengthen the regular education and training of tour guides, improve the comprehensive quality of tour guides, let guides integrate the idea of "tourists first" into their practical work, improve the professional ethics of tour guides, and consciously ensure the interests of tourists and prevent the occurrence of tourist complaints from the root.

\section{C.Improve the complaint mechanism for tourism}

No matter how good the rules are, they must be strictly enforced in order to produce good results. The first is to improve the supervision of the tourism market, and to improve the tourism complaints mechanism, and to increase the intensity of comprehensive law enforcement. The second is to cooperate with Yunnan tourism regulatory authorities to establish a working group to further clarify the division of their respective functions to avoid shirking the responsibility when confronted with law enforcement issues. The third is to promote the tourism industry to be highly integrated with the Internet, cloud computing, big data, artificial intelligence, and adopt a series of advanced technologies such as intelligent search, multi-terminal integration, heterogeneous big data, AR, VR, AI, etc, to create " one mobile phone tour Yunnan" this APP platform to to realize the one key complaint of each link of food, shelter, travel, shopping and entertainment.Through "one mobile phone tour Yunnan" APP reconstructs the complaint processing mechanism, the tourist can complain through sends the information, the voice message and so on, the complaint processing is like the electronic commerce shopping to check the logistics information, the processing process is completely open to tourists, achieve one-click complaints, timely response, hierarchical acceptance, linkage disposal, real-time feedback, time-limited conclusion. The fourth is to establish a territorial management system for time-limited conclusion, examination reward and punishment and responsibility investigations of travel complaints, on the relevant functional departments to complete the task of supervision and assessment, put forward rewards and punishments or accountability advice to achieve the unified and rapid handling of tourism complaints.

\section{D.Increase tourism education for tourists}

Many tourists who make complaints are due to "knowing that there are tricks but they feel they are lucky." After purchasing cheap travel routes, local specialties and other goods, they regretted being deceived,this is the reason why the "low price tour", "zero tour fee" repeatedly banned and frequently happened in recent years. The first is to strengthen the guidance and education of tourists, improve the ability of tourists to distinguish consumption. The second is to open and transparent tourism consumer commodity prices through modern means of communication, such as network, two-micro, to inform tourists in the form of tourism fraud may be encountered in the local, in many ways to improve the tourists' perception of a single low-cost tourism, low-cost consumption. The third is to help tourists better identify fake and shoddy tourist commodities, improve the ability of tourists to prevent fraud, and prevent the occurrence of tourism complaints.

\section{E. Rebuilding the brand image of tourism}

In recent years, the tourism industry in Yunnan Province has been affected by the negative events, many negative events of the tourist disputes and injuries have damaged the image of the tourism industry in Yunnan Province, and it is urgent to regain the good brand image of "the South of the Clouds". Firstly, it is necessary to strengthen marketing promotion, strengthen the positive image of Yunnan tourism, and implement the tourism image upgrading plan, always take marketing promotion as an unremitting and important work, 
transfer the signal and determination of the fundamental improvement of the Yunnan tourism market environment to the outside world, and reshape the warm and hospitable tourist image of the people in Yunnan. The second is to strengthen the communication with the network media, timely pay attention to the complaints of tourists through the network media, use the network media to carry on social public relations scientifically, and maintain the positive tourism image.The third is to constantly increase efforts to speed up the transformation and upgrading of the tourism industry, with the idea that "Yunnan has only one scenic spot, this scenic spot is called Yunnan" to create a tourism brand, with the target image of"tourist tourism freedom"and "government management services everywhere"to create world-class tourism. The fourth is to use modern information means to timely handle visitor complaints and create an image of a tourism site that is fair and protects the interests of tourists to attracts tourists. For example,in "one mobile phone tour Yunnan" line of every business, government departments, industry associations, tourists give credit evaluation to him, reconstruction of the integrity system, and regain the confidence of tourists.

\section{REFERENCES}

[1] Li Qifan. First anniversary of the severely regulating tourism market order in Yunnan [N/OL]. Yunnan Tourism Administration Network, 2018-4-17. http://ynta.gov.cn/Item/37259.aspx. (In Chinese)

[2] Li Qifan. The tourism reception situation in the province in 2017 [N/OL]. Yunnan Tourism Administration Network, 2018-1-30. http://ynta.gov.cn/Item/36181.aspx. (In Chinese)

[3] Lu Wanqing, Zhang Dong, Li Lulu, du Jingchuan. An analysis of the characteristics and influencing factors of tourism complaints from the perspective of tourists-A case study of Yunnan Province [J]. Tourism resources: 2017-11-21(11). (In Chinese)

[4] Wang Jian et al. Theory and Policy of Chinese Government Regulation [M]. Beijing: Economic Science Press, 2008(6):171-242. (In Chinese)

[5] Wu Wenzhi. Research on Government Regulation of Public Scenic Spots in China [M]. Beijing: Tourism Education Press, 2011. (In Chinese)

[6] Xu Feng, Li Chenggang. Research on the functions of Government Tourism Management from the Perspective of Economics [J]. Tourism Science 2005(6). (In Chinese)

[7] Zhang Fan, Yang Wenming. Cancel fixed-point shopping, cut off the chain of interests, this time, Yunnan hit the seven-inch low-price travel [N]. People's Daily, 2017-3-28 (10). (In Chinese)

[8] Zhang Hongfeng, Yang Hui, et al. The change of Government Regulation in Western countries and the Reform of Chinese Government Regulation [M]. Beijing: Economic Science Press, 2007. (In Chinese)

[9] Zhang Wenling. "Yunnan travel entered the warming period after curettage of bone and toxin [N]. China Youth Daily. 2018-4-19 (08). (In Chinese)

[10] Zhou Bin, Zheng Yi. The "breaking wrist" and "scratching" of the tourism industry have achieved remarkable results - Interview with NPC deputy and Governor of Yunnan Province Yan Chengfa [N]. Economic Daily, 2018-3-11. (In Chinese) 